\title{
O BRINCAR LIVRE DE GÊNEROS
}

\author{
Camila da Silva Rondon Campos ${ }^{1}$ \\ Cleidiane Gonçalves da Silva1 ${ }^{2}$ \\ Marta Maria Rodrigues de Miranda ${ }^{3}$ \\ Mickyciele da Silva Caldas Almeida ${ }^{4}$ \\ Rosidete Conceição da Silva Gaudêncio ${ }^{5}$ \\ Ruan Felipe da Silva Cesário ${ }^{6}$ \\ Tânia Aparecida Oliveira Ferreira ${ }^{7}$
}

RESUMO: Este artigo tem como objetivo observar como as crianças manifestam desigualdades de gênero em relação a determinados brinquedos e jogos. A questão em questão é estudar como os professores reagem a esse ponto de vista. Visa abordar essa questão por meio de um breve relato sobre a definição de gênero, o brincar na educação infantil, como as construções de gênero fazem sentido e como essa relação interfere na identidade de gênero. Para obter esta análise, foi realizado um estudo bibliográfico para fundamentar a teoria, conta principalmente com: Eliot, (2013), Aaud, (2017), Belotti, (1987), entre outros defendendo a importância da igualdade de gênero na infância e no ensino e aprendizagem.

Palavras-chaves: Infância. Gênero Humano. Brinquedos. Brincadeiras.

\footnotetext{
I Graduada em Pedagogia pela Universidade Federal de Mato Grosso - UFMT, Especialista em Educação Infantil pelas Faculdades Integradas de Várzea Grande - FIAVEC.

${ }^{2}$ Graduada em Pedagogia pela Universidade Norte do Paraná - UNOPAR, Especialista em Educação Infantil com Ênfase nos Anos Iniciais pela Faculdade FAIPE.

${ }^{3}$ Graduada em Pedagogia pela Universidade Paulista - UNIP, Especialista em Educação Especial e Educação Inclusiva pela UNINTER - Centro Universitário Internacional.

${ }_{4}^{4}$ Graduada em Pedagogia pela Universidade Pitágoras - UNOPAR, Especialista em Educação Infantil: prática pedagógica pela Faculdade - FAVENI.

5 Graduada em Pedagogia pelo Centro Universitário Cândido Rondon - UNIRONDON, Especialista em Docência na Educação Infantil pela Universidade Federal de Mato Grosso - UFMT, Especialista em Relações Raciais no Contexto do EJA - Educação de Jovens e Adultos pela Universidade Federal de Mato Grosso UFMT, Especialista em Informática na Educação.

${ }^{6}$ Graduado em Pedagogia pela Faculdade INVEST de Ciências e Tecnologia, Especialista em Atendimento Educacional Especializado - AEE pela Faculdade INVEST de Ciências e Tecnologia.

7 Graduada em Pedagogia pela Universidade Luterana do Brasil - ULBRA, Especialista em Educação de Jovens e Adultos e Economia Solidária - EJA/ECOSOL pela Universidade Federal de Mato Grosso - UFMT.
} 
ABSTRACT: This article aims to observe how children manifest gender inequalities in relation to certain toys and games. The issue at hand is to study how teachers react to this point of view. It aims to address this issue through a brief report on the definition of gender, playing in early childhood education, how gender constructions make sense and how this relationship interferes with gender identity. To obtain this analysis, a bibliographic study was carried out to support the theory, mainly with: Eliot, (2013), Aaud, (2017), Belotti, (1987), among others defending the importance of gender equality in childhood and in the teaching and learning.

Keywords: Childhood. Human Gender. Toys. Play

\section{INTRODUÇÃO}

Ao se falar em educação infantil, é necessário informar sobre a livre escolha de brinquedos e brincadeiras, pois o brincar é divertido e o sexo não importa. Para uma criança, qual é a diferença entre um menino brincando com uma boneca e uma menina de skate? Porque tudo ao seu redor capta sua atenção, tornando-os mais dispostos a experimentar, e quanto mais livre uma criança for para explorar e explorar, mais rico será seu aprendizado.

Este artigo tem como objetivo estudar como crianças da educação infantil expressam as relações de gênero por meio do brincar, mostrando o impacto dessa segmentação na infância e na idade adulta.

A criança está na fase de descoberta e, portanto, acabará sendo influenciada pelos adultos: o menino brinca com carrinho e a menina brinca com boneca, buscando entender a resposta do professor às escolhas das crianças quando elas brincam.

A questão abordada é a brincadeira de meninos versus brincadeiras de meninas ou brinquedos de meninos e brinquedos de meninas e como os professores reagem a este ponto de vista. Nossa visão da educação infantil hoje é fragmentária, considerando as posições da educação secundária familiar, que se vêem como objetos de imitação, com uma delimitação específica das crianças. da aprendizagem em seu contexto real.

Podemos perceber como a questão de gênero existe na educação infantil, com a divisão de atividades, atitudes e comportamentos no cotidiano e além da sala de aula, onde a divisão se dá "naturalmente" nas crianças. 
O artigo foi desenvolvido a partir de uma pesquisa bibliográfica para compreender como as crianças manifestam as relações de gênero diante de determinados brinquedos e jogos.

\section{DESENVOLVIMENTO}

\section{I Definição de gênero}

Quanto à interpretação da identidade de gênero, ela pode ser definida como um conjunto de seres com a mesma origem ou que possuem características comuns da mesma espécie, família, raça ou distinção social entre homens e mulheres, que varia conforme a cultura e afeta o estatuto, o papel social e a identidade de gênero de cada indivíduo na comunidade em que está inserido. Isso inclui como os indivíduos definem seu gênero, de tal forma que descobrimos que os significados são frequentemente representativos das culturas dominantes.

\footnotetext{
Vale ressaltar que as relações de gênero, do modo como estão organizadas em nossa sociedade, são uma máquina de produzir desigualdades. As visões naturalistas sobre mulheres, meninas, homens e meninos representam travas para a superação dessa situação (AUAD, 2017, p. 19).
}

Essas diferenças, no entanto, não são naturais, mas social e historicamente construídas com base em padrões normativos sobre o que significa ser homem e o que significa ser mulher. Outro fato que podemos citar em alguns casos é que a palavra gênero, como relata a autora, é utilizada para falar sobre questões de desigualdade social. A identidade é uma característica fundamental da experiência humana que nos permite ver nossas constituições como sujeitos da sociedade. Assim, gênero se refere à identidade que uma pessoa identifica, ou seja, para se tornar homem ou mulher é preciso passar por um processo denominado "socialização de gênero", a partir da expectativa de que a cultura de uma sociedade está vinculada para cada sexo, desta forma, a sociedade estabelece de antemão, a partir do momento em que nasce uma criança (homem ou mulher), os padrões a que deve obedecer e quais os comportamentos "aceitáveis" para cada gênero. 


\title{
2.2 O brincar na educação infantil
}

É importe sensibilizar os educadores de que o brincar deve ser vivenciado desde a infância, pois brincar faz parte de um processo de aprendizagem mais significativo e prazeroso, torna-se uma via de mão dupla, por um lado o ato de brincar e, por outro, aprender, despertar e desenvolver motivações, linguagem, pensamentos e sentimentos. Por meio da interação, a criança desenvolve hipóteses e a capacidade de compreensão do outro, pois isso ocorre na forma de relações e de reconstrução do mundo ao seu redor do ponto de vista lógico da criança. Conforme as Diretrizes Curriculares para a Educação Infantil:

\begin{abstract}
A motricidade, a linguagem, o pensamento, a afetividade e a sociabilidade são aspectos integrados e se desenvolvem a partir das interações que, desde o nascimento, a criança estabelece com diferentes parceiros, a depender da maneira como sua capacidade para construir conhecimento é possibilitada e trabalhada nas situações em que ela participa. Isso por que, na realização de tarefas diversas, na companhia de adultos e de outras crianças, no confronto dos gestos, das falas, enfim, das ações desses parceiros, cada criança modifica sua forma de agir, sentir e pensar (2013, p. 86).
\end{abstract}

Cada criança possui um ritmo e uma forma única de se relacionar, de agir, de sentir e de pensar, que deve ser levada em consideração pelo educador, na busca da compreensão e conciliação dos sentidos que a criança constrói e evolui a cada interação, seja com objetos (brinquedos) ou com seus próprios pares por meio de jogos que lhes proporcionam experiências, facilitam a realização e formam identidades.

A atitude de explorar e manipular brinquedos e jogos permite que as crianças estimulem uma resposta, permitindo assim a exposição a diferentes brinquedos e jogos num ambiente relacional e de trocas onde existem semelhanças de situações e problemas do quotidiano, tendo o brinquedo como auxiliar de brincar, sejam concretos ou ideológicos, projetados ou simplesmente usados. Representa uma concepção em que a criança pode produzir por meio de qualquer substância, de forma lúdica e definitiva.

[...] vemos meninas que já adquiriram o reflexo condicionado boneca acalanto e, assim que recebem nas mãos uma boneca, já a apertam ao peito e acalenta, os adultos esquecendo-se de que esse comportamento é apenas o resultado de suas instruções, exclamam que se trata de um milagre "biológico". Tão pequena mais com extinto materno. Isso os enche de alegria, pois o fenômeno é percebido como 


\begin{abstract}
o sintoma tranquilizados da normalidade. Posteriormente, se há de insistir para que as meninas continuem brincando com as bonecas, pois esse jogo é considerado um verdadeiro aprendizado para a futura função materna ao passo que o garotinho que manifestasse preferências como esta, seria dissuadido e estimulado para se ocupar com outros tipos de jogos impostos aos garotos e as meninas de tal modo que gostos "particulares" em relação a brinquedos após a idade de $4 / 5$ anos começam a significar que o menino ou menina não aceitaram os seus papeis e que por conseguinte alguma coisa não funcionou (BELOTTI, 1987, p.73-74).
\end{abstract}

O ambiente em que se relacionam é primordial, pois as próprias crianças começam a criar esse tipo de preconceito contra as pessoas do sexo oposto. Por outro lado, para construir uma geração mais confiante e consciente, é preciso fortalecer a igualdade de gênero para que se tornem cidadãos de sua própria escolha.

\title{
2.3 A questão de gênero na educação infantil
}

$\mathrm{Na}$ infância, as crianças estão em processo de construção de sua própria identidade e de catalogação de objetos como brinquedos, cores, como roupas de "meninos" e "meninas", o que acaba criando uma distorção na imagem.

Após o período de curiosidade pela diferença entre os sexos, por volta dos 5 aos 6 anos, as questões de gênero passam a ter um papel central na construção da identidade. Isso se reflete nas ações e interações das crianças, que tendem a separar espontaneamente meninos e meninas.

Nessa perspectiva o Referencial Curricular Nacional para a Educação Infantil (1998, p. 4I) entende que a criança deve brincar com as possibilidades relacionadas tanto ao papel do homem como ao da mulher, no entanto não ressalta como devem ser essas atividades, as quais devem ficar a critério do educador e isso requer uma atenção por parte do professor para não reproduzir padrões estereotipados quanto ao que se trata dos papeis do homem e da mulher, por exemplo "homem não chora e que a mulher não briga".

\subsection{As relações de gêneros nas brincadeiras}

Nos dias atuais, o tema é pouco abordado na educação infantil. Meninos e meninas são divididos nas brincadeiras e brinquedos, os próprios professores até mesmo sem intenção contribuem para que os alunos se tornem seletivos, por exemplo: você é menina não pode brincar com isso ou aquilo, o mesmo acontece com os meninos, atitudes que não parecem 
culturalmente "normal", se aparenta estranho como se o brincar fosse algo que necessitasse de uma atenção especial.

A maioria das escolas não estão preparadas para abordar a situação. O que os pais dirão a respeito do assunto?

A questão de gênero é pouco estudada e entendida, e ela se confunde muito, como se isso mudasse o sexo das crianças. Os professores precisam rever a questão de gênero quanto a jogos, brinquedos e brincadeiras e não confundir essa prática social como homossexualidade. No mundo atual, essas brincadeiras se misturam, causando uma inibição de comportamento, provocando intolerância, muitas vezes essa forma diversificada de brincar, se dá pelo medo que esses brinquedos ou brincadeiras possam influenciar na vida sexual da criança, sendo que essa maneira de brincar refere-se a uma construção social.

Assim, o contato que a criança, nessa fase tem com os brinquedos e brincadeiras é de grande relevância para o seu desenvolvimento, evidenciando suas habilidades de adaptação. É um meio de aprendizagem espontâneo que envolve o prazer de experimentar e descobrir.

A diferença entre imitação e identificação consiste justamente no fato de a imitação pode ser uma repetição de comportamentos que produz fraca ressonância afetiva à criança que vê outra pessoa andando em triciclo tenta andar também. Ao passo que na identificação a criança age conforme o modelo do outro. Tudo depende como é o outro (BELOTTI, i987, p. 56).

Dessa maneira, a criança observa ativamente tudo o que se passa ao seu redor e a partir da imitação começa a interagir e construir novas relações sociais através da identificação ampliando seu horizonte. Nessa fase, o brincar é fundamental para o desenvolvimento da identidade e autonomia. Nas brincadeiras, as crianças desenvolvem várias funções, se socializam por meio da interação, experimentação e a divisão entre as brincadeiras por gêneros podem ser muito prejudiciais, porque limitam o universo lúdico da criança.

O brincar "de verdade" é muito melhor. Até os brinquedos masculinos e femininos mais tradicionais permitem, em certa extensão, que a criança explore, manipule, movimente-se, sinta, fale e negocie. O problema é até que ponto. O brincar do menino e o da menina tendem, cada um, a exercitar algumas habilidades mentais mais que outras; se cada sexo só brincar na sua "zona apropriada", as crianças acabarão fortalecendo as mesmas áreas cerebrais que já tendem a funcionar melhor desde o nascimento (ELIOT, 2013, p. 158). 
Em vista disso, aos poucos as crianças descobrem o brincar na aprendizagem, abrindo múltiplas possibilidades sem imposições. A curiosidade do brincar com algo novo do habitual, quanto mais livre a criança for para explorar e descobrir, mais rica será a sua experiência e aprendizagem.

Os momentos de brincadeiras servem para que elas brinquem, não importa o gênero. O que realmente importa é ser criança. Conforme Kishimoto (20oo, p. 68) o brinquedo aparece como um pedaço de cultura colocado ao alcance da criança. É seu parceiro na brincadeira. A manipulação do brinquedo leva a criança à ação, à representação, a agir e a imaginar.

É preciso desconstruir essa visão estereotipada e pensar na criança como um todo, que em sua subjetividade aproveita a liberdade que tem para escolher um brinquedo para brincar. A criança não nasce sabendo brincar, ela precisa aprender por meio das interações com outras crianças e com os adultos.

Conforme Belotti, que vivenciou, em creches, episódios em que a criança tinha liberdade para escolher entre brinquedos, objetos e atividades que até por volta dos três anos as meninas brincavam tanto quanto os meninos com automóveis, aeroplanos, navios, etc.

\footnotetext{
Vi meninas de $18 / 20$ meses que passaram horas a fio tirando de um saquinho de pano uma série de pequenos automóveis, aviões, helicópteros, navios, trenzinhos, alinhavam-nos em cima de um tapete e os empurravam com o mesmo prazer e a mesma concentração dos garotinhos que passam uma manhã inteira fazendo faxina, lavando mesas e dando lustre em sapatos. Mais tarde esse fenômeno desaparece os garotos já aprenderam a escolher o brinquedo "certo" porque sabem que não irão receber o brinquedo "errado" (Belotti 1987, p. 78).
}

A questão de gênero, às vezes, pode se confundir com sexismo, e que a falta de conhecimento sobre o assunto acaba mistificando o contexto em si.

Assim como cita Auad (2017, p. 15): “A escola pode ser o lugar no qual se dá o discriminatório - aprendizado da separação - ou, em contrapartida, pode ser uma importante instância de emancipação e mudança.

[...] acho que vale a pena uma cutucada ocasional para tornar as crianças conscientes de seus preconceitos. Pois, embora, fatores inatos claramente inclinem meninos e meninas para diferentes tipos de brinquedos, (...) especialmente por sua própria percepção emergente de ser menino ou menina (ELIOT, 2013, p. 133). 
As representações sobre o masculino e feminino, além do sexo dos sujeitos, são utilizados para organizar as práticas escolares. São, contudo, silenciados nos discursos. Dessa forma, não se pensa sobre como a utilização desses elementos na organização do trabalho na escola pode promover situações de desigualdade (AUAD, 2017, p. 30).

O referencial teórico deste artigo explica e reforça que a escola pode ser um lugar de grandes desigualdades, ao mesmo tempo que pode ser um ambiente que contribui para diversas mudanças no futuro, não só das crianças, mas de outros adultos.

Nota-se, então, que a problemática em questão foi a visão fragmentada do professor em relação aos brinquedos e brincadeiras destinados a ambos os sexos. Trabalhar com a igualdade de gênero na escola possibilita ao aluno uma visão diferenciada dos papéis sociais difundidos entre a população nas suas várias esferas, exaltando valores como o respeito ao próximo e o tratamento digno e livre de qualquer forma de preconceito.

\section{CONCLUSÃO}

Através desse artigo, podemos refletir sobre a questão de gênero na educação infantil e a consequência que isso traz para a desigualdade de gênero ao passar dos anos.

A probabilidade do desigual, como aponta Auad (2017, p. 19). "Vale a pena ressaltar que as relações de gêneros, do modo como estão organizadas em nossa sociedade, são uma máquina de produzir desigualdades".

É notável que a maioria dos professores não estão preparados para certas mudanças, e deve quebrar estereótipos para ser e fazer a diferença para que a sociedade de amanhã seja melhor do que é hoje e que as crianças possam se divertir sem medo e sem se sentirem livres para escolher.

Nesse processo, o papel do professor é fomentar situações que facilitem o ensino, acreditando que são esses valores na infância que são aprendidos e praticados na idade adulta, e que não devemos ensinar apenas a ler e a escrever, aliás, ser facilitadores, verificadores, formar cidadãos críticos para um futuro mais igualitário. 
Novos estudos podem ser realizados para obter resultados mais detalhados sobre a desigualdade de gênero na educação infantil, com o objetivo de corrigir os preconceitos que os professores carregam consigo.

\section{REFERÊNCIAS}

AUAD, Daniela. Educar meninas e meninos: relações na escola. $2^{\underline{a}}$ ed. São Paulo: Contextos, 2017.

BELOTTI, Elena Gianini. Educar para a submissão. Tradução de Ephrain Ferreira Alves. 6⿳亠丷厂 ed. Petrópolis: Vozes, 1987.

BRASIL. Revisão do DCNEI. IN. Revisão Diretrizes Curriculares Nacionais para a Educação Básica. Brasil, 2013.

ELIOT, Lise. Cérebro azul ou Rosa: o impacto das diferenças de gênero na educação. Porto Alegre: Penso, 2013.

KISHIMOTO,Tizuko Morchida (org). Jogo, brinquedo, brincadeira e a educação. $4^{\underline{a}}$ ed. São Paulo: Cortez, 2000. 